\title{
Effect of TRH on the secretion of prolactin in ewes at various stages of pregnancy and in non-pregnant ewes during the breeding season and seasonal anoestrus
}

\author{
B. P. Fitzgerald, Janet D. Evins and F. J. Cunningham \\ Department of Physiology \& Biochemistry, The University of Reading, Whiteknights, Reading, \\ Berkshire RG6 2AJ, U.K.
}

\begin{abstract}
Summary. The concentrations of prolactin in plasma were measured before and after the injection of TRH in pregnant ewes and in non-pregnant ewes during the breeding season and seasonal anoestrus. During the first 80 days of pregnancy basal concentrations of prolactin were low and stable but thereafter increased progressively to reach maximum values at Day 140. During a comparable time of year (DecemberApril) basal concentrations of prolactin in non-pregnant ewes were not significantly different from those found between Days 20 and 120 of pregnancy. At other times of the year basal concentrations of prolactin in non-pregnant ewes were elevated during anoestrus and declined markedly at the onset of the breeding season. In pregnant and non-pregnant ewes the responsiveness of the pituitary gland to stimulation with TRH was significantly correlated with the basal concentration of prolactin in plasma: the raised concentration of prolactin at Day 140 of pregnancy and in July in non-pregnant ewes was associated with the greatest release of prolactin from the pituitary gland. A change in the responsiveness of the pituitary gland may play an important role in the overall control of prolactin secretion in the ewe.
\end{abstract}

\section{Introduction}

The concentration of prolactin in plasma during pregnancy in the ewe gradually increases from values of $<20 \mathrm{ng} / \mathrm{ml}$ at Day 100 of pregnancy to maximum values $(>250 \mathrm{ng} / \mathrm{ml}$ ) around the time of parturition (Kann \& Denamur, 1974; Lamming, Moseley \& McNeilly, 1974; Burd, Lemons, Markowski, Meschia \& Niswender, 1976). The increased secretion of prolactin is functionally important with respect to subsequent milk yield post partum (Kann et al., 1978) but the mechanisms regulating the secretion of prolactin during pregnancy are not understood. Kann \& Denamur (1974) suggested that the increased secretion of prolactin might be associated with the well known rise in the circulating concentration of oestradiol-17/3. However, a close examination of the literature on the time course of the changes in concentrations of prolactin and oestradiol-17 $\beta$ in plasma during pregnancy reveals that the prolactin values increase before any major change in oestradiol-17 $\beta$ concentration is seen (see Burd et al., 1976; Tsang, 1978). It would seem, therefore, that some other explanation must be sought to account for the observed changes in the pattern of prolactin secretion. One possibility is that there is an alteration in the responsiveness of the pituitary gland to endogenous stimulation. Since thyrotrophin-releasing hormone (TRH) is known to stimulate prolactin secretion in the ewe (Lamming et al., 1974) the present study was designed to examine the ability of TRH to provoke the release of prolactin at various times during pregnancy. It was anticipated that the amount of 
prolactin released in response to stimulation with a low dose of TRH might reflect an altered responsiveness of the pituitary gland.

In non-pregnant ewes a rise in the plasma concentration of prolactin is associated with increasing daylength (Walton, McNeilly, McNeilly \& Cunningham, 1977; Thimonier, Ravault \& Ortavant, 1978; Fitzgerald, 1979; Walton, Evins, Fitzgerald \& Cunningham, 1980). This is perhaps relevant to the rise seen during pregnancy because in most British breeds of sheep parturition occurs at the end of the breeding season when daylength is increasing. It is therefore possible that the changes in prolactin secretion characteristic of pregnancy stem not from the physiological status but rather from environmental influences. This contingency was taken account of in the present study by determining the effect of TRH in non-pregnant ewes at comparable times of the year.

The investigation was also extended to non-pregnant ewes in seasonal anoestrus to provide additional information relevant to understanding of the overall regulation of prolactin secretion in the ewe.

\section{Materials and Methods}

\section{Animals}

Pregnant ewes. Six Border Leicester ewes were selected at random and mated, between 19 November and 5 December 1978, with a fertile ram fitted with a harness and marking crayon. The failure to exhibit overt oestrous behaviour 17 days later was taken to indicate that the ewes were pregnant and this was subsequently confirmed. The ewes were kept as a single flock at pasture and given an additional diet of concentrates and hay.

Non-pregnant ewes. Six Border Leicester ewes, selected at random, were kept as a single flock at pasture with supplemental hay as necessary. During the breeding season the occurrence of behavioural oestrus was detected by a vasectomized ram fitted with a harness and marking crayon.

\section{Administration of TRH}

Pregnant ewes. Five ewes at Day 20 of pregnancy and 6 ewes at Days 50, 80, 100, 120 and 140 were penned individually in an open shed and each ewe was fitted with an indwelling jugular venous catheter. The cannulae were maintained patent by flushing with saline $(9 \mathrm{~g}$ $\mathrm{NaCl} / \mathrm{l}$ ) containing 50 i.u. heparin $/ \mathrm{ml}$. The next day each ewe received an intravenous injection of $5 \mu \mathrm{g}$ synthetic TRH (Hoechst Pharmaceuticals) in $1 \mathrm{ml} \mathrm{saline.}$

Non-pregnant ewes. In the period between November 1978 and October 197966 experiments were carried out. During the breeding season each experiment was performed, as described for pregnant ewes, during the luteal phase of the oestrous cycle (Days 9-15) when it is known that the plasma concentrations of prolactin are relatively stable (Kann \& Denamur. 1974). Throughout the remainder of the year experiments were conducted at monthly intervals.

\section{Collection of blood samples}

In each experiment blood $(5 \mathrm{ml})$ was collected every $15 \mathrm{~min}$ for $2 \mathrm{~h}$ before the injection of TRH and every $5 \mathrm{~min}$ for $30 \mathrm{~min}$ after the injection and then every $15 \mathrm{~min}$ for the next $1.5 \mathrm{~h}$ and every $20 \mathrm{~min}$ for the final $3 \mathrm{~h}$. All blood samples were centrifuged within $30 \mathrm{~min}$ of collection at $1600 \mathrm{~g}$ for $15 \mathrm{~min}$ and the plasma separated and stored at $-20^{\circ} \mathrm{C}$ until assayed for prolactin. 


\section{Prolactin assay}

Prolactin was measured with a specific double-antibody radioimmunoassay as described by Walton et al. (1980) and slightly modified by Fitzgerald \& Cunningham (1981). All samples from each animal were assayed at random in a single batch and the precision of the assays as reflected by the inter- and intra-assay coefficients of variation was always $<10 \%$. The sensitivity of the assay $\left(\mathrm{B} / \mathrm{B}_{0}=90 \%\right)$ was $1.4 \mathrm{ng} \mathrm{NIH-P-S6} / \mathrm{ml}$.

\section{Statistical procedures}

The concentrations of prolactin in the period before the injection of TRH were compared in pregnant and non-pregnant ewes (December-April) by using the Student-Newman-Keuls test for multiple comparisons between means based on unequal sample sizes (Sokal \& Rohlf, 1969). Before statistical analysis all plasma concentrations of prolactin were transformed to logarithms to stabilize variance.

The responsiveness of the pituitary gland to the stimulating effects of TRH was assessed by measuring the total area under the curve of prolactin release from 0 to $30 \mathrm{~min}$ after the injection. The basal concentration at zero time was calculated from the 3 samples taken immediately before the injection of TRH. Areas were calculated by the trapezoidal approximation (Abramowitz \& Stegun, 1968) only for those ewes in which both a stable basal concentration was observed at a time 0 and maximum concentrations were found within 30 min after injection of TRH. The relationship between basal concentrations of prolactin in the 2 -h period before the injection of TRH and the areas under the response curve was determined by regression analysis.

\section{Results}

\section{Basal concentrations of prolactin}

The changes in basal concentrations of prolactin in the 6 pregnant and 6 non-pregnant ewes are shown in Text-fig. 1. During the first 80 days of pregnancy the mean \pm s.e.m. concentrations of prolactin in plasma were low and stable and ranged between $9 \pm 1 \mathrm{ng} / \mathrm{ml}$ at Day 20 , and $6 \pm 1 \mathrm{ng} / \mathrm{ml}$ at Day 80 . Thereafter the concentrations increased to $12 \pm 1 \mathrm{ng} / \mathrm{ml}$ at Day 100 and maximum concentrations at Day $140(246 \pm 16 \mathrm{ng} / \mathrm{ml})$. In some ewes at Day 20 higher plasma prolactin concentrations were observed at the start of sampling than in the period immediately before the injection of TRH whereas in subsequent experiments, between Days 50 and 120 of pregnancy, a more stable pattern of secretion was observed. However, at Day 140 of pregnancy there was again evidence for 5 ewes of stress-induced release of prolactin at the start of sampling.

In the period between December and February mean \pm s.e.m. basal concentrations of prolactin in 6 non-pregnant ewes were low (February, $9 \pm 1 \mathrm{ng} / \mathrm{ml}$ ), but thereafter the concentrations increased significantly $(P<0.05)$ to $15 \pm 1 \mathrm{ng} / \mathrm{ml}$ in March and reached a value of $59 \pm 4 \mathrm{ng} / \mathrm{ml}$ in April. The gradual increase observed in plasma prolactin concentrations between December and March was not related to a change in breeding activity since all the ewes studied in March subsequently exhibited overt oestrous behaviour. In contrast all ewes studied during April, when prolactin concentrations were considerably elevated, were in anoestrus.

Comparisons of the observed changes in basal prolactin concentrations between pregnant and non-pregnant ewes showed that the concentrations between Days 20 and 100 of pregnancy were not significantly different from those in non-pregnant ewes between December and February. However, the plasma concentration of prolactin at Day 120 of pregnancy was 


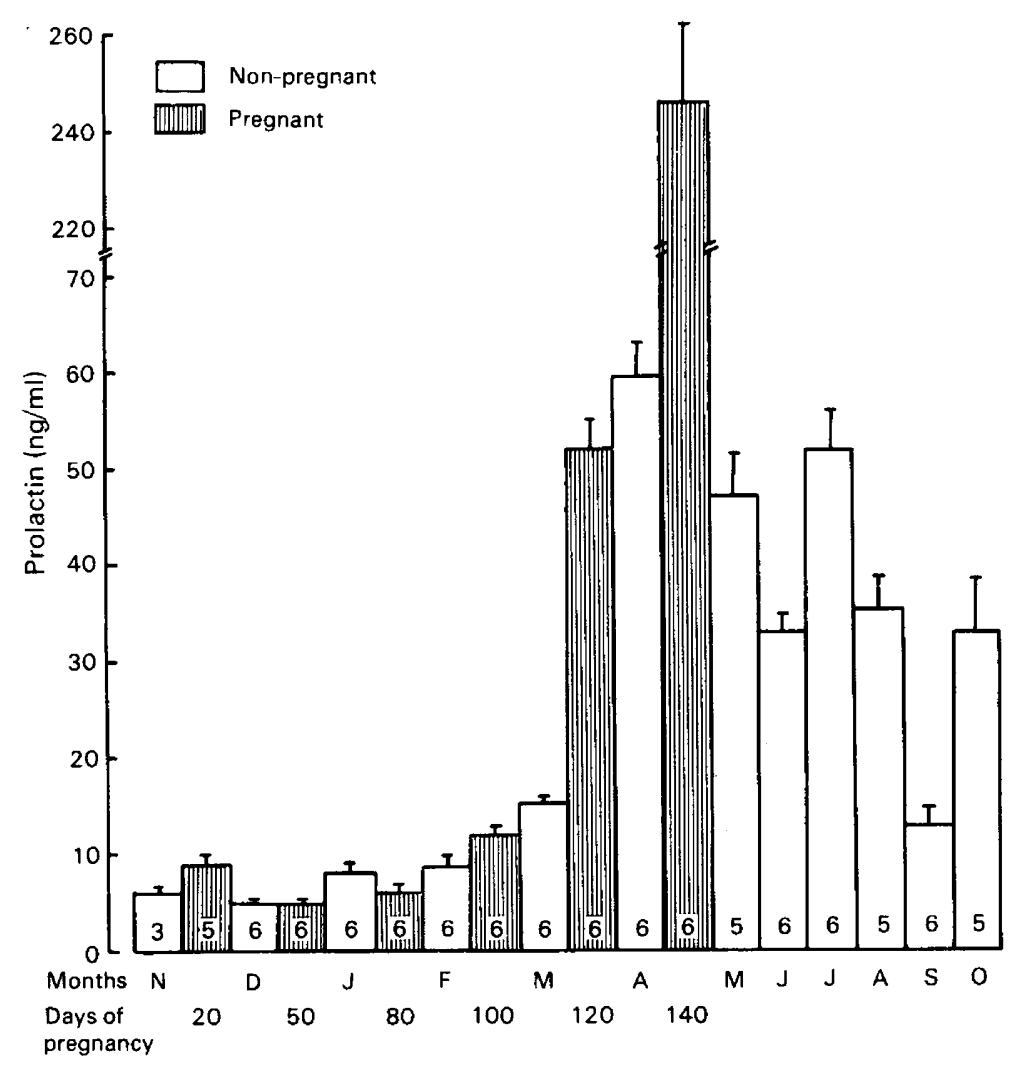

Text-fig. 1. Mean \pm s.e.m. plasma concentrations of prolactin in ewes during pregnancy and in non-pregnant ewes during the breeding season and seasonal anoestrus. The numbers of animals in each group are indicated at the foot of each column.

significantly $(P<0.05)$ greater than that observed during March in non-pregnant ewes but not different from that during April. Values at Day 140 of pregnancy were greater $(P<0.05)$ than those of non-pregnant ewes between December and April.

Throughout the remainder of the year basal concentrations of prolactin in non-pregnant ewes were elevated during anoestrus and declined markedly at the onset of the breeding season (late October). However, there was considerable between-ewe variation in the concentration of prolactin during October since 4 of the 5 ewes studied during this period were anoestrous. Furthermore, 2 of these ewes (Nos 1 and 2) exhibited overt oestrous behaviour 1 and 2 days respectively after the end of the investigation. The fact that the concentration of prolactin in Ewe 1 was considerably greater than that in the remaining 4 ewes might be accounted for by an increased release around the time of oestrus.

\section{Pituitary gland responsiveness}

The changes in the responsiveness of the pituitary gland to the stimulating effects of TRH in pregnant and non-pregnant ewes are shown in Text-fig. 2. Of the 101 experiments carried out in pregnant and non-pregnant ewes 5 were rejected since on these occasions either a stable basal concentration of prolactin was not observed in the period immediately before injection of TRH or the maximum value of prolactin did not occur within $30 \mathrm{~min}$ of the injection. During pregnancy there was a pronounced and significant $(P<0.05)$ increase in the response of the 


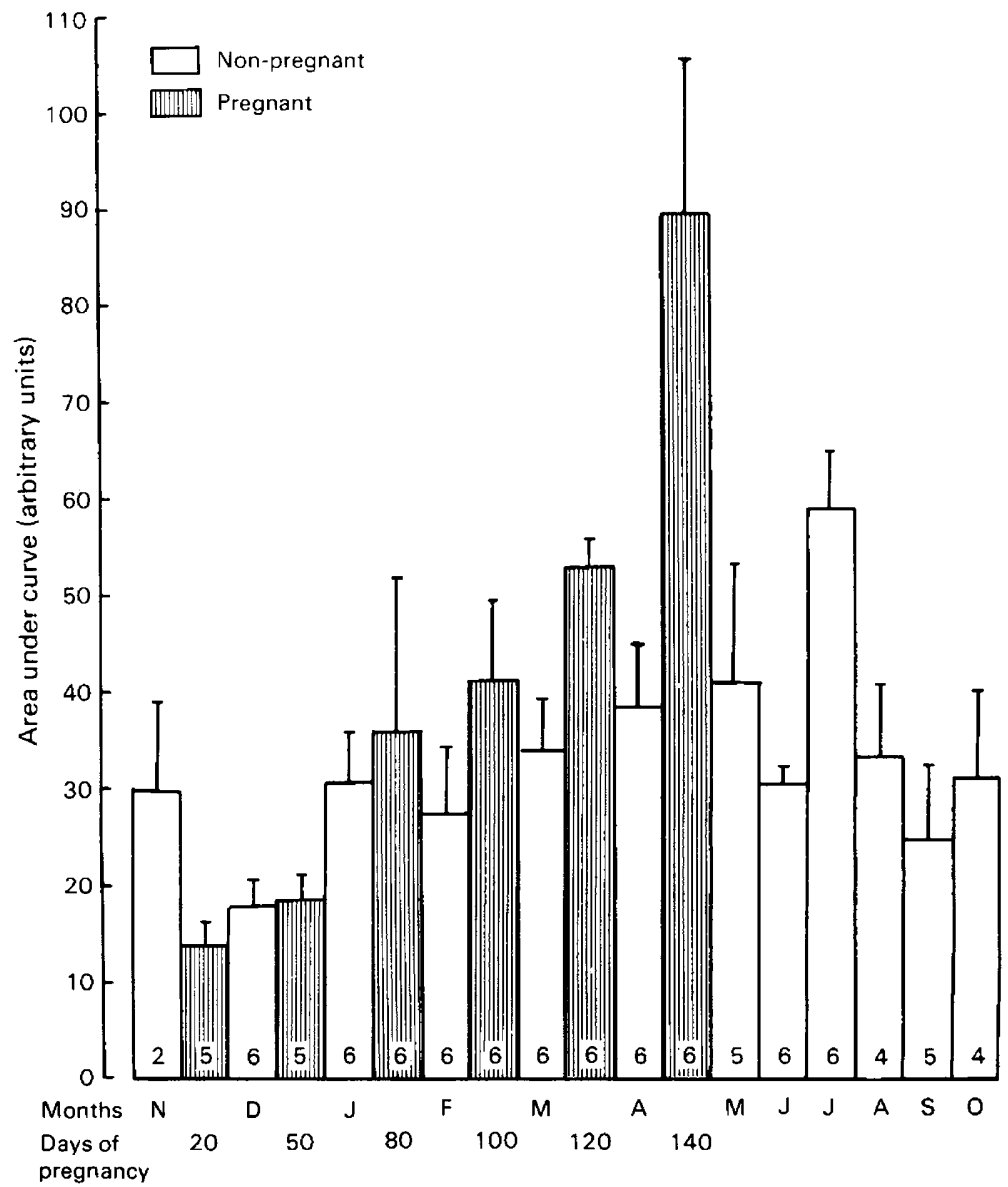

Text-fig. 2. Mean \pm s.e.m. changes in the area under the prolactin response curve during $30 \mathrm{~min}$ after treatment of ewes with $5 \mu \mathrm{g} \mathrm{TRH}$ at various stages of pregnancy or during the breeding season and seasonal anoestrus. The numbers of animals in each group are indicated at the foot of each column.

pituitary gland to stimulation with TRH such that the value at Day 140 was approximately 9-fold greater than that at Day 20. Comparison of the changes in pregnant and non-pregnant ewes indicated that the response in pregnant ewes between Days 50 and 100 was not signifcantly different from that found in non-pregnant ewes between December and April. However, the responses at Days 120 and 140 of pregnancy were significantly $(P<0.05)$ greater than all of the values found during the period between December and April. In pregnant and nonpregnant ewes the response of the pituitary gland to stimulation with TRH was significantly correlated with the basal concentration of prolactin $(r=0.76, n=34, P<0.001$, and $r=0.37$, $n=62, P<0.01$, respectively). Consequently the raised concentrations of prolactin found in non-pregnant ewes during July were associated with the greatest release of prolactin seen after stimulation with TRH.

\section{Discussion}

In an earlier study Kann \& Denamur (1974) showed that during pregnancy in the ewe plasma concentrations of prolactin gradually increase from low levels at Day 100 to reach maximum values around the time of parturition. Furthermore, they attributed this rise in the concentration 
of prolactin to an increase in the circulating concentration of oestradiol-17(). Although the present findings clearly support their observations that plasma prolactin concentrations increase after Day 100 of pregnancy the results do not suggest that the increase, at least for the first 120 days of pregnancy, is due to an increase in the concentration of oestradiol-17 $\beta$ since a similar increase in prolactin concentrations was noted in non-pregnant ewes studied at the same time of year. There was, however, a further increase in plasma prolactin concentrations at Day 140 of pregnancy and the concentration at this time was substantially greater than that found in non-pregnant ewes. This suggests that during late pregnancy a factor other than that of a change in daylength is responsible for the increase in prolactin concentrations.

The present results suggest that a change in responsiveness of the pituitary gland towards the end of pregnancy may contribute to the overall control of prolactin secretion at this time. However, in a similar study Chamley (1978) found no obvious differences in the prolactin response to TRH throughout pregnancy. There are several possibilities to account for the discrepancy between the two studies. In the first place no indication was given in the earlier study of the time of the year during which the animals were pregnant. An effect of season cannot, therefore, be excluded. Moreover, Chamley (1978) reported basal concentrations of plasma prolactin early in pregnancy (Day 40) that were about 10 times higher than those generally accepted to prevail at this time, and, again at variance with other studies, no increase in the basal concentration of prolactin was observed until term.

An important event occurring during late pregnancy in the ewe is a decline in the plasma concentration of progesterone; although sequential daily blood samples were not collected in the present study several observations by other workers have established that in the ewe plasma progesterone concentrations fall markedly during the final 2-15 days before parturition (Fylling, 1970; Burd et al., 1976). This decline in the plasma concentration of progesterone has been implicated in the control of prolactin secretion at the end of pregnancy (Burd et al., 1976). For instance, treatment of ewes with high doses of progesterone $(75 \mathrm{mg}$ ) immediately after Caesarean section at Day 141 of pregnancy suppressed the increased secretion of prolactin which normally follows this operation in the ewe (Kann et al., 1978), suggesting an important relationship between the increase in prolactin and the decline in progesterone concentrations during the last 2-15 days before parturition. However, the appreciable increase in the responsiveness of the pituitary gland to the stimulating effects of TRH at Day 140 in the present study indicates that the potential of the pituitary gland to release prolactin, in response to stimulatory factors, e.g. oestradiol-17 $\beta$, is enhanced during late pregnancy. Therefore, despite the major changes in oestrogens, specifically oestradiol-17/, that occur during the last 1-2 days before parturition, the earlier levels might be sufficient to stimulate the release of prolactin because of a change in the responsiveness of the pituitary gland. Further studies are needed to determine the relative contributions of progesterone and oestradiol-17p in the control of prolactin secretion during pregnancy in the ewe.

In agreement with previous studies a seasonal variation in the plasma concentration of prolactin was found in non-pregnant ewes exposed to normal variations in daylength and temperature (Walton et al., 1977, 1980; Thimonier et al., 1978). The highest concentrations of prolactin were observed during April and July and the lowest during December. During the breeding season there was an increase in the concentration during March and this increase was associated with the last oestrous cycle of that breeding season. The significance of this finding is not clear, but may be related to the changing sensitivity of the hypothalamus to the negative feedback action of oestradiol-17\% which is known to occur at the end of the breeding season (Karsch, Goodman \& Legan, 1980).

In pregnant and non-pregnant ewes the responsiveness of the pituitary gland to stimulation with TRH was correlated with the basal concentration of prolactin, thus accounting for the observed increase in the responsiveness associated with late pregnancy and seasonal anoestrus when plasma prolactin concentrations were clearly elevated. The question arises, therefore, as to 
the extent, if any, a change in the responsiveness of the pituitary gland to stimulatory factors may play in the overall control of prolactin secretion; the observed changes could be the cause or the consequence of an alteration in the basal concentration of prolactin. Nevertheless, the present findings clearly demonstrate that in the ewe raised concentrations of prolactin are associated with an increased responsiveness of the pituitary gland to the stimulating effects of TRH.

We thank the staff of the Animal Production Research Unit, University of Reading, for care of the animals; Dr S. L. Dombey, Hoechst Pharmaceuticals, Hounslow, Middlesex, for supplies of synthetic TRH; and the Wellcome Trust (7743/1.5) and Agricultural Research Council (AG45/157) for grants to defray the costs of this research.

\section{References}

Abramowitz, M. \& Stegun, I. A. (1968) Handbook of Mathematical Functions, p. 885. Dover Publications, Inc., New York.

Burd, L.I., Lemons, J.A., Markowski, E.L., Meschia, G. \& Niswender, G. (1976) Mammary blood flow and endocrine changes during parturition in the ewe. Endocrinology 98, 748-754.

Chamley, W.A. (1978) Prolactin response to synthetic TRH in pregnant ewes. J. Reprod. Fert. 52, 297-299.

Fitzgerald, B.P. (1979) A study of the endocrinology of the ewe, pre, peri and post-partum and during seasonal anoestrus. Ph.D. thesis, University of Reading.

Fitzgerald, B.P. \& Cunningham, F.J. (1981) Effect of removal of lambs or treatment with bromocriptine on plasma concentrations of prolactin and FSH during the post-partum period of ewes lambing at different times during the breeding season. J. Reprod. Fert. 61, 141-148.

Fylling, P. (1970) The effect of pregnancy, ovariectomy and parturition on plasma progesterone levels in sheep. Acta endocr., Copenh. 65, 273-283.

Kann, G. \& Denamur, R. (1974) Possible role of prolactin during the oestrous cycle and gestation in the ewe. J. Reprod. Fert. 39, 473-483.

Kann, G., Carpentier, M.-C., Fevre, J., Martinet, J., Maubon, M., Meusnier, C., Paly, J. \& Vermeire, N. (1978) Lactation and prolactin in sheep, role of prolactin in initiation of milk secretion. In Progress in Prolactin Physiology and Pathology, pp. 201-212. Eds C. Robyn \& M. Harter. Elsevier/North Holland Press, Amsterdam.

Karsch, F.J., Goodman, R.L. \& Legan, S.J. (1980) Feedback basis of seasonal breeding: test of an hypothesis. J. Reprod. Fert. 58, 521-535.

Lamming, G.E., Moseley, S.R. \& McNeilly, J.R. (1974) Prolactin release in sheep. J. Reprod. Fert. 40, $151-168$.

Sokal, R.R. \& Rohlf, F.J. (1969) Biometry, pp. 242-245. W. H. Freeman \& Co., San Francisco.

Thimonier, J., Ravault, J.P. \& Ortavant, R. (1978) Plasma prolactin variations and cyclic ovarian activity in ewes submitted to different light regimens. Annls Biol. anim. Biochim. Biophys. 18, 1229-1235.

Tsang, C.P.W. (1978) Plasma levels of estrone sulphate, free estrogens and progesterone in the pregnant ewe through gestation. Theriogenology 10,97-100.

Walton, J.S., McNeilly, J.R., McNeilly, A.S. \& Cunningham, F.J. (1977) Changes in concentration of follicle-stimulating hormone, luteinizing hormone, prolactin and progesterone in the plasma of ewes during the transition from anoestrus to breeding activity. $J$. Endocr. 75, 127-136.

Walton, J.S., Evins, J.D., Fitzgerald, B.P. \& Cunningham, F.J. (1980) Abrupt decrease in daylength and short-term changes in the plasma concentrations of FSH, LH and prolactin in anoestrous ewes. J. Reprod. Fert. 59, 163-171.

Received 24 April 1980 